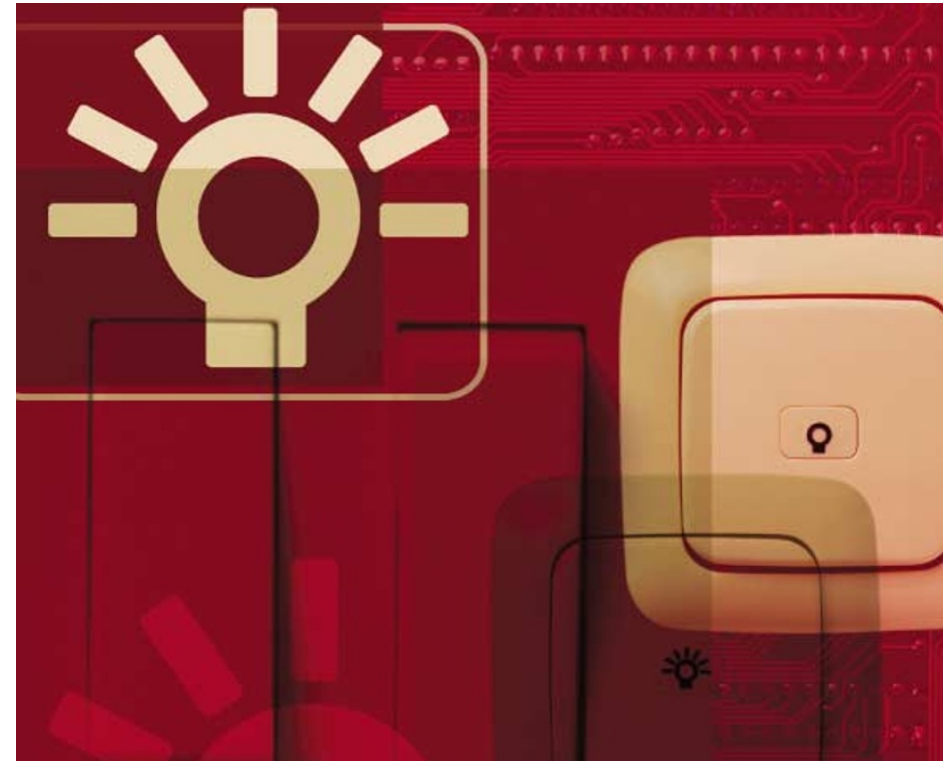

INNATE IMMUNITY

\section{An off-switch for TLR signalling}

Much has been learned in the past few years about how the innate immune system functions. Dysregulation of innate immunity is thought to contribute to the pathogenesis of diseases such as Crohn's disease and inflammatory bowel disease, but the mechanisms by which innate immunity is regulated are not well understood. Now, Richard Flavell's group have shown that interleukin-1 (IL-1)-receptor-associated kinase M (IRAK-M) is a negative regulator of Toll-like receptor (TLR) signalling.

TLR-mediated recognition of pathogen-associated molecular patterns (PAMPs) on microorganisms leads to the activation of innate immunity. After ligand engagement, the adaptor protein MYD88 is recruited to the TLR. On recruitment to the signalling complex by MYD88, IRAK is phosphorylated, which allows it to dissociate from the complex and bind to downstream molecules such as TRAF6. This leads to the activation of various downstream effectors. The authors generated IRAK-M-knockout mice to investigate the role of IRAK-M - the expression of which is restricted to macrophages and monocytes - in TLR signalling.

IRAK-M-deficient macrophages produced more cytokines (IL-12 p40, IL-6 and TNF) than wild-type macrophages in response to stimulation with various PAMPs. Similarly, infection of the $I R A K-M^{-/-}$macrophages with live or dead Gram-negative and Gram-positive bacteria led to the enhanced production of cytokines compared with wild-type cells. IRAK- $M^{-/-}$mice were orally infected with Salmonella typhimurium and the effect of the IRAK-M deficiency on intestinal inflammation was examined. A greater number of enlarged Peyer's patches (PPs) was observed in the deficient mice, and the PPs had severe inflammatory infiltrates compared with wild-type mice.

Next, the authors investigated the effects of IRAK-M deficiency on TLR signalling pathways. TLR engagement on IRAK- $M^{-/-}$macrophages

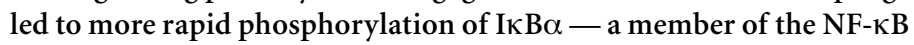
family - and a faster and more extensive phosphorylation of JNK, p38 and ERK1/2, which indicates that IRAK-M might negatively regulate these pathways.

So, how does IRAK-M function as a negative regulator? On the basis of a series of co-immunoprecipitation experiments, the authors suggest that, rather than inhibiting the association of IRAK with TRAF6, IRAK-M inhibits the dissociation of IRAK from the TLR signalling complex, and so prevents it from activating downstream mediators.

Elaine Bell

(0) References and links

ORIGINAL RESEARCH PAPER Kobayashi, K. et al. IRAK-M is a negative regulator of Toll-like receptor signaling. Cell 110, 191-202 (2002)

FURTHER READING O'Neill, L. A. Toll-like receptor signal transduction and the tailoring of innate immunity: a role for Mal? Trends Immunol. 23, 296-300 (2002)

\section{IN BRIEF}

\section{TRANSPLANTATION}

Donor-type CD4 ${ }^{+} \mathrm{CD} 25^{+}$regulatory T cells suppress lethal acute graft-versus-host disease after allogeneic bone-marrow transplantation.

Hoffmann, P. et al. J. Exp. Med. 196, 389-399 (2002)

CD4 ${ }^{+}$CD25+ immunoregulatory $T$ cells: new therapeutics for graft-versus-host disease.

Cohen, J. L. et al. J. Exp. Med. 196, 401-406 (2002)

$\mathrm{CD} 4{ }^{+} \mathrm{CD} 25^{+}$regulatory $\mathrm{T}$ cells are known to have an important role in inducing tolerance to allogeneic organ transplants. These two studies show that these cells can also suppress graft-versushost disease (GVHD; the main complication of allogeneic haematopoietic stem-cell transplantation) in mouse models. Cohen et al. show that $\mathrm{CD} 4^{+} \mathrm{CD} 25^{+} \mathrm{T}$ cells that are naturally present in the graft regulate GVHD, because their removal from the graft accelerated the development of this disease. The addition of freshly isolated $\mathrm{CD} 4^{+} \mathrm{CD} 25^{+} \mathrm{T}$ cells at the time of grafting delayed or even prevented GVHD. Hoffman et al. show that interleukin- 10 produced by transplanted $\mathrm{CD} 4^{+} \mathrm{CD} 25^{+}$ $\mathrm{T}$ cells is required for full protection and that these cells must be of donor origin.

\section{DENDRITIC CELLS}

Characterization of a new subpopulation of mouse $\mathrm{CD} 8 \alpha^{+} \mathrm{B} 220^{+}$dendritic cells endowed with type-1 interferon production capacity and tolerogenic potential. Martín, P. et al. Blood 100, 383-390 (2002)

The authors describe a new $\mathrm{B} 220^{+}$subpopulation of immaturelike mouse dendritic cells (B220 ${ }^{+}$DCs) that are present in the thymus, bone marrow, spleen and lymph nodes, and that express low levels of MHC and co-stimulatory molecules. These B220 ${ }^{+}$ DCs share ultrastructural features with human plasmacytoid cells and, in line with this, they produced type I interferon after virus stimulation. In addition, these DCs had reduced T-cell stimulatory potential, which indicates that they might be a physiological subset of tolerogenic DCs.

\section{T-CELL DEVELOPMENT}

Thymocyte development in early growth response gene-1-deficient mice.

Bettini, M. et al. J. Immunol. 169, 1713-1720 (2002)

In this study, Bettini et al. investigated the role of the transcriptional regulator early growth response gene 1 (Egr1) in thymocyte development. They looked at thymocyte development in $\mathrm{Egrl}^{-/-}$mice on a normal polyclonal T-cell receptor (TCR) background and on different TCR-transgenic backgrounds. The overall thymic cellularity of the $E g r 1^{-/-}$mice was increased, which indicates that Egr1 regulates the size of the thymus. Egr1 is also important for the positive selection of $\mathrm{CD}^{+}$and $\mathrm{CD} 8^{+}$ single-positive $\mathrm{T}$ cells and is a positive regulator of $\mathrm{Id} 3$ and $\mathrm{Bcl}$ expression in response to TCR signalling in double-positive thymocytes. 